\title{
Management of a premature low birth weight neonate with Ebstein anomaly and persistent circular shunt using modified Starnes procedure
}

\author{
Mimi Xiaoming Deng, BHSc, ${ }^{\mathrm{a}}$ Roxanne Kirsch, MD, ${ }^{\mathrm{b}}$ Edgar Jaeggi, MD, ${ }^{\mathrm{c}}$ and Osami Honjo, MD, PhD, ${ }^{\mathrm{a}, \mathrm{d}}$ \\ Toronto, Ontario, Canada
}

\footnotetext{
From the ${ }^{\mathrm{a} D i v i s i o n}$ of Cardiovascular Surgery, Labatt Family Heart Centre, ${ }^{\mathrm{b}}$ Division of Cardiac Critical Care, Department of Critical Care Medicine, and ${ }^{\mathrm{C}}$ Division of Cardiology, Labatt Family Heart Centre, The Hospital for Sick Children, Toronto, Ontario, Canada; and ${ }^{\mathrm{d}}$ Department of Surgery, University of Toronto, Toronto, Ontario, Canada

Disclosures: The authors reported no conflicts of interest.

The Journal policy requires editors and reviewers to disclose conflicts of interest and to decline handling or reviewing manuscripts for which they may have a conflict of interest. The editors and reviewers of this article have no conflicts of interest.

Consent was granted by the subject patient's parents to publish this case report.

Received for publication Jan 28, 2021; accepted for publication Jan 28, 2021; available ahead of print Feb 6, 2021.

Address for reprints: Osami Honjo, MD, PhD, Division of Cardiovascular Surgery, Labatt Family Heart Center, The Hospital for Sick Children, 555 University Ave, Toronto, Ontario, Canada M5G1X8 (E-mail: osami. honjo@sickkids.ca).

JTCVS Techniques 2021;7:208-11

2666-2507

Copyright (c) 2021 The Authors. Published by Elsevier Inc. on behalf of The American Association for Thoracic Surgery. This is an open access article under the CC BY-NC-ND license (http://creativecommons.org/licenses/bync-nd/4.0/).

https://doi.org/10.1016/j.xjtc.2021.01.040
}

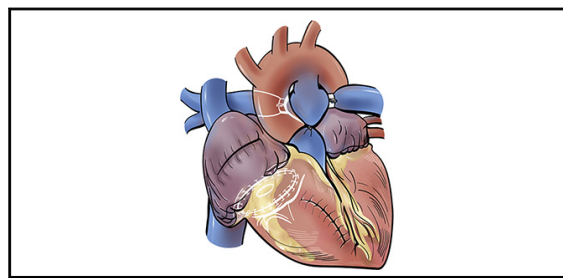

Modified Starnes procedure with 3-mm fenestrated patch closure of the tricuspid annulus.

\section{CENTRAL MESSAGE \\ A critical neonatal Ebstein anomaly can be successfully rescued through the modified Starnes procedure.}

See Commentaries on pages 212 and 214 . $\square$ Video clip is available online.

Fetuses with the severe Ebstein anomaly (EA) involving a circular shunt through a patent ductus arteriosus (PDA) and regurgitant pulmonary and tricuspid valves are at high risk for hydrops fetalis and intrauterine demise. ${ }^{1}$ Such neonates require emergent treatment immediately after birth. Treatment options are limited in preterm low birth weight neonates with a significant risk of intracranial hemorrhage. ${ }^{2}$ Here we report a very preterm low birth weight neonate with severe EA and a circular shunt, successfully managed with a modified Starnes procedure, pulmonary artery (PA) banding, and PDA (Video 1).

\section{CASE DESCRIPTION}

A fetus with severe EA and a circular shunt developed progressive hydrops. Decision was made to deliver electively by cesarean section at 32 weeks of gestation to prevent intrauterine demise. A cardiac operating room (OR) was set up adjacent to the mother's OR to allow for immediate surgical intervention. After birth, the neonate was immediately intubated and brought to the cardiac OR. Postnatal transthoracic echocardiography confirmed the diagnosis: nonanatomic pulmonary atresia with no anterograde flow, a significant circular shunt, and very
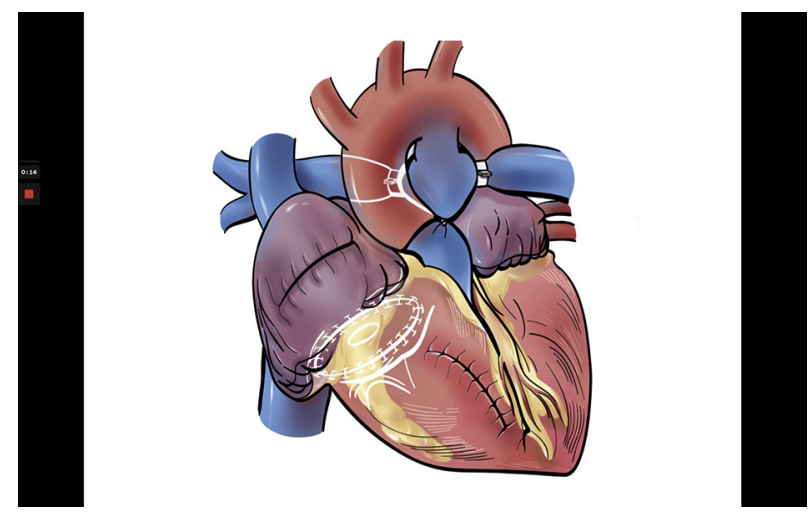

VIDEO 1. Video summary of the case and our institution's approach to stratification of disease severity in patients with fetal diagnosis of severe Ebstein anomaly. Video available at: https://www.jtcvs.org/article/S26662507(21)00127-9/fulltext. 


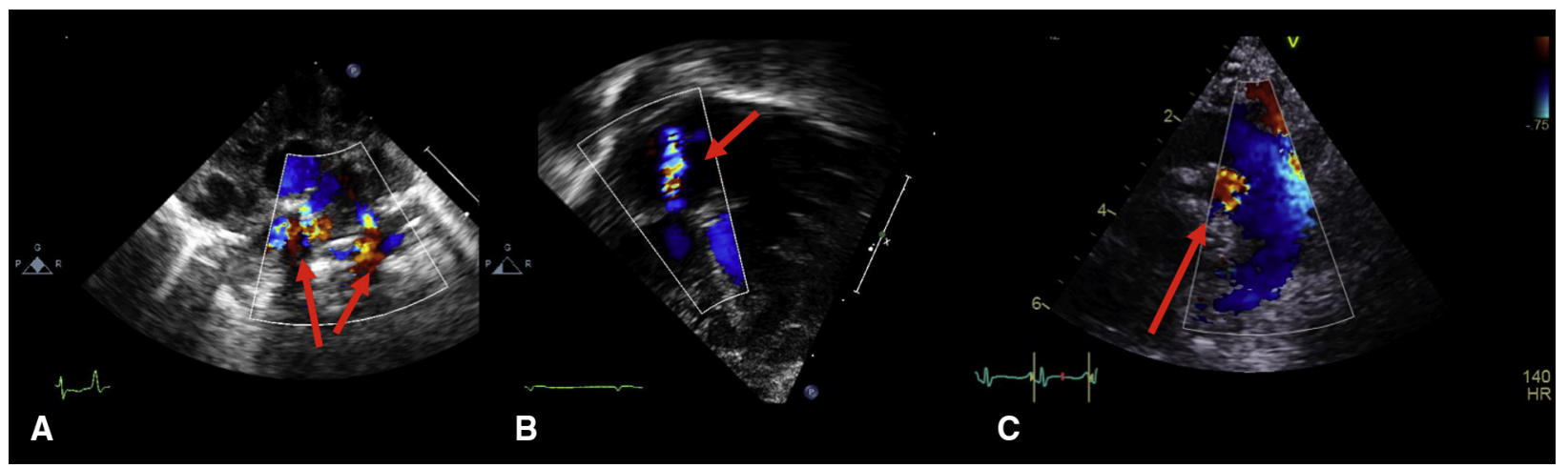

FIGURE 1. Postoperative echocardiograms for the modified Starnes procedure. A, Short-axis view showing well-seated bilateral pulmonary artery bands (arrow). B, Fenestration through the tricuspid valve patch. C, Large patent ductus arteriosus on prostaglandin E1 with continuous left-to-right shunting.

low $(<20 \mathrm{~mm} \mathrm{Hg})$ estimated right ventricular systolic pressure. Emergent main PA ligation and right atrial reduction were performed without cardiopulmonary bypass. Sternal closure was electively delayed. Prostaglandin E1 maintained ductal patency and PA perfusion.

Several hours later, the patient developed progressive low cardiac output and lactic acidosis due to high pulmonary circulation despite maximal medical therapies. Therefore, it was decided to undertake bilateral PA banding at bedside to control pulmonary blood flow (Figure 1, A). However, after achieving temporary hemodynamic stability, the patient continued to deteriorate, necessitating emergent reoperation.

Cardiopulmonary bypass was instituted using ascending aortic and bicaval cannulation with anterograde cardioplegia. The patient underwent a modified Starnes procedure, consisting of tricuspid valve closure using a 3-mm fenestrated Gore-Tex patch (Figure 1,B), atrial septectomy, and right atrial and ventricular plication at 20 hours of life (Figure 2). PA bands and the PDA were maintained (Figure 1,C) rather than placing a Blalock-TaussigThomas (BTT) shunt. Owing to poor oxygenation and low cardiac output with left ventricular dysfunction, the patient required extracorporeal membrane oxygenation (ECMO) initially but was weaned off ECMO at postoperative day 6 with reasonable ventricular and pulmonary function. The postoperative course was complicated by mediastinitis and anuric renal failure requiring peritoneal dialysis. Once renal recovery occurred, the patient underwent placement of a $3.5-\mathrm{mm}$ right BTT shunt, bilateral PA debanding, bilateral PA patch reconstruction, and PDA ligation at age 3 months (corrected age, 1 month). Cardiac catheterization at age 7 months (corrected 5 months) revealed a PA pressure of 16 to $17 \mathrm{mmHg}$ and a pulmonary vascular resistance index of 1.8 Woods units. Bidirectional cavopulmonary shunt was uneventfully performed at age 9 months (corrected 7 months). Currently, the patient is awaiting Fontan completion.

\section{DISCUSSION}

Elimination of the circular shunt is the immediate step to secure systemic oxygen delivery in neonates with extreme EA. However, patients still face significant problems with high pulmonary circulation and resultant low systemic oxygen delivery.

Two-stage palliation of main PA ligation preceded by modified Starnes has been reported previously, with BTT placement as a part of the Starnes procedure. ${ }^{3,4}$

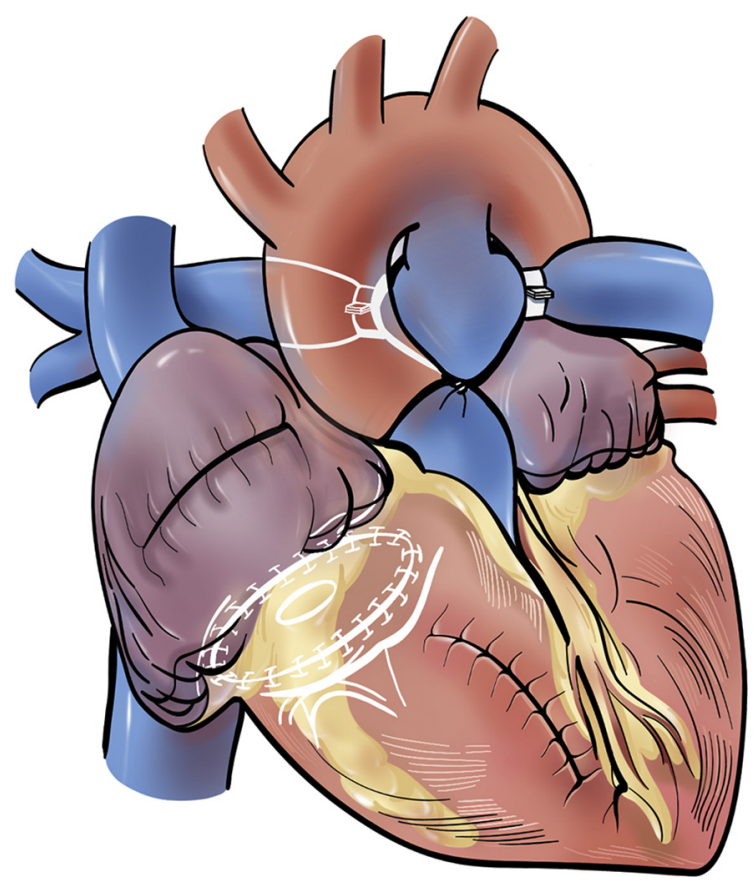

FIGURE 2. Graphic description of the modified Starnes procedure involving tricuspid valve closure using a 3-mm fenestrated Gore-Tex patch, atrial septectomy, and right atrial and ventricular plication. Pulmonary artery bands and the patent ductus arteriosus were kept in place instead of inserting a Blalock-Taussig-Thomas shunt. 


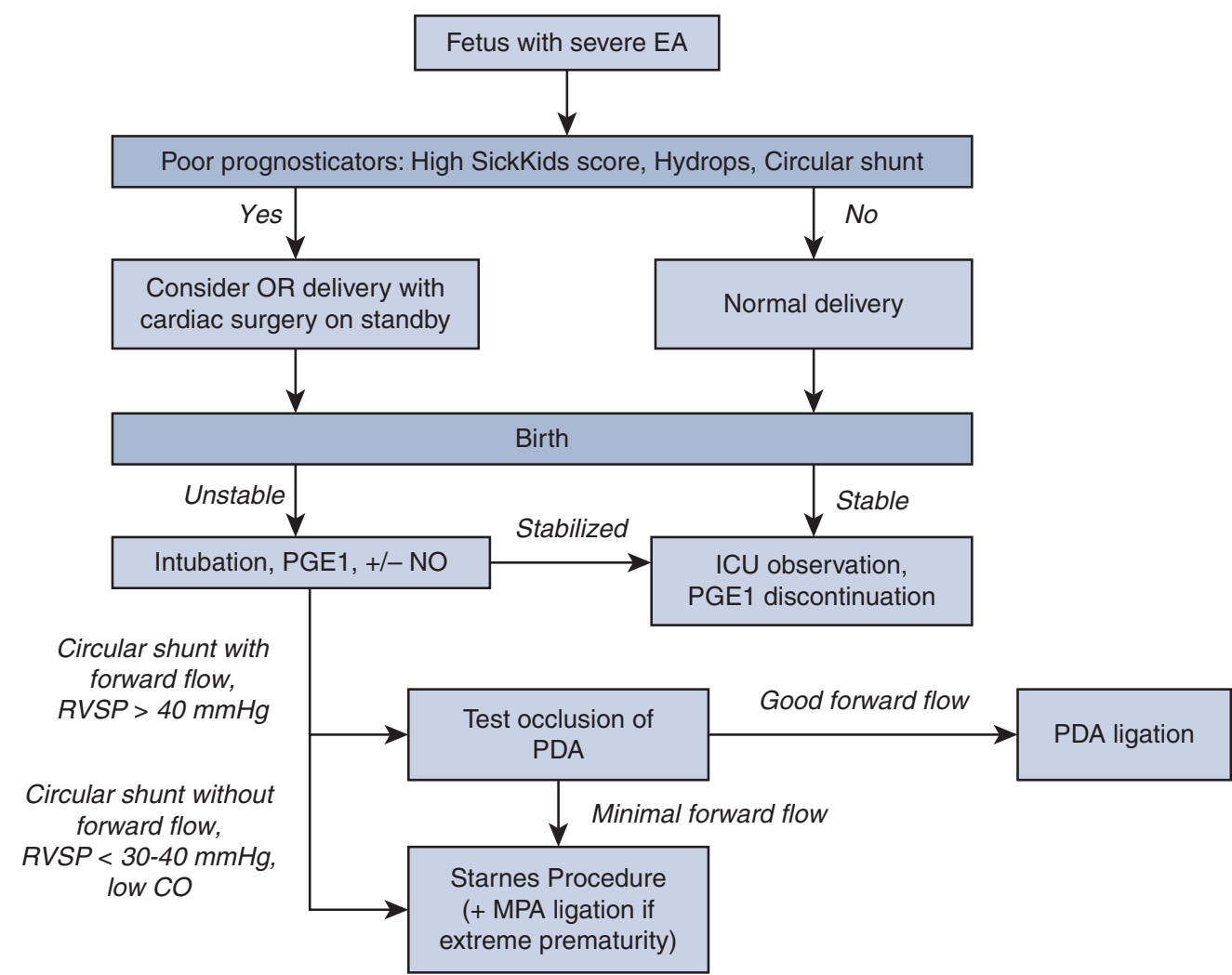

FIGURE 3. The Hospital for Sick Children's management algorithm for fetal diagnosis of severe Ebstein anomaly (EA). OR, Operating room; $P G E 1$, prostaglandin E1; $N O$, nitric oxide; ICU, intensive care unit; $R V S P$, right ventricular systolic pressure; $C O$, cardiac output; $P D A$, patent ductus arteriosus; $M P A$, main pulmonary artery.

We posit that BTT placement in our $1.25-\mathrm{kg}$ neonate would not have solved the high pulmonary blood flow issue owing to an extremely unfavorable shunt size-tobody weight ratio. Bilateral PA banding and PDA is a better approach to titrating and optimizing pulmonary blood flow by tightening or loosening the bands as

TABLE 1. Fetal severity by SickKids score

\begin{tabular}{|c|c|c|c|}
\hline \multirow[b]{2}{*}{ Variable } & \multicolumn{3}{|c|}{ Weighting } \\
\hline & $\mathbf{0}$ & 1 & 2 \\
\hline Cardiothoracic ratio & $<0.65$ & $0.65-0.75$ & $>0.75$ \\
\hline Right atrial area index & $<0.75$ & $0.75-1.0$ & $>1.0$ \\
\hline Pulmonary forward flow & Normal & Reduced & Absent \\
\hline Tricuspid regurgitation & No or mild & > Mild & $\begin{array}{c}\text { Moderate/ } \\
\text { severe }\end{array}$ \\
\hline Doppler gradient & - & $\geq 40 \mathrm{~mm} \mathrm{Hg}$ & $\begin{array}{c}<40 \mathrm{~mm} \\
\mathrm{Hg}\end{array}$ \\
\hline Pulmonary regurgitation & No & Yes & Yes \\
\hline End-diastolic UA flow & - & Antegrade & $\begin{array}{l}\text { Absent or } \\
\text { reversed }\end{array}$ \\
\hline
\end{tabular}

UA, Umbilical artery. Reproduced from Wertaschnigg and colleagues. opposed to placing the smallest available $(3 \mathrm{~mm}) \mathrm{BTT}$ shunt. We previously published a technique of BTT shunt banding to restrict blood flow based on an established formula ${ }^{5}$; however, banding a $3-\mathrm{mm}$ shunt is prone to significant stenosis with any additional tightening. PA band titration is hypothesized to be a more reliable way to control pulmonary blood flow.

We speculate that the need for modified Starnes as a rescue procedure was due to the massively dilated right ventricle compressing the left ventricle and the lungs, contributing to low cardiac output. Although the patient required postoperative ECMO, decompression of the right ventricle improved left ventricular filling and facilitated ECMO separation.

Our institution follows a management algorithm (Figure 3) for fetal/neonatal cases with severe EA, which assigns them to medical management and/or biventricular repair based on echocardiographic and radiographic stratification of disease severity using a 7-item scale known as the SickKids score (Table 1). ${ }^{1}$ In newborns with a failing, low-pressure- generating right ventricle, we triage to the primary Starnes procedure. Our patient had a SickKids score of 14. For patients with a low or moderate SickKids score, ${ }^{1}$ we prefer conservative therapy of discontinuing 
prostaglandin E1 with or without PDA ligation and nitric oxide administration.

\section{References}

1. Wertaschnigg D, Manlhiot C, Jaeggi M, Seed M, Dragulescu A, Schwartz SM, et al. Contemporary outcomes and factors associated with mortality after a fetal or neonatal diagnosis of Ebstein anomaly and tricuspid valve disease. Can J Cardiol. 2016;32:1500-6.

2. Wei D, Azen C, Bhombal S, Hastings L, Paquette L. Congenital heart disease in low-birth-weight infants: effects of small for gestational age (SGA) status and maturity on postoperative outcomes. Pediatr Cardiol. 2015;36: 1-7.

3. Yanase Y, Watanabe M, Ishikawa N, Higami T. Surgical treatment for neonatal Ebstein's anomaly with circular shunting. Interact Cardiovasc Thorac Surg. 2012;14: 886-8.

4. Kajihara N, Asou T, Takeda Y, Kosaka Y, Onakatomi Y, Miyata D, et al. Rapid two-stage Starnes procedure for a symptomatic neonate with Ebstein anomaly. Ann Thorac Surg. 2010;90:2073-5.

5. Atlin CR, Haller C, Honjo O, Jegatheeswaran A, Van Arsdell GS. Balancing pulmonary blood flow: theory, in vitro measurements, and clinical correlation of systemicto-pulmonary shunt banding. J Thorac Cardiovasc Surg. 2016;152:1343-52.e2. 